\title{
editorial
}

\section{The role of the archaeological excavation in the 21st century}

Excavation is the heart of archaeology. In the minds of the general public, archaeology is synonymous with excavation. We belong to a discipline that is, perhaps uniquely, defined by its dominant method of evidence collection and generation of data.

And yet most of us accept that excavation is only a part of what we do. It is one means, among many, of gathering primary data. In the past, perhaps, archaeology used to be all about excavation, but that is no longer the case today. A plethora of other methods for data collection now exist. Even more significantly, for some periods and regions (though not for all) we now possess a vast archive of primary data, much of which has been only minimally analysed and interpreted, if at all. Can we continue to defend the costly excavation of archaeological sites, and the accrual of even more data? Especially in those instances where the material recovered only adds to an existing body of data on types of site, periods or regions we already know well, one might ask: haven't we dug enough now?

An additional complicating factor is the widespread failure of archaeologists to ensure that the results of excavation are published and accessible. Too many site reports never see the light, or exist only as thin manuscripts in unmarked filing cabinets. How can we go on excavating new sites when we cannot deal with those excavations we have already done? Should we, then, consider newly introduced obligations to publish within a certain time limit after completion of the excavation or after each season of excavation as a blessing in disguise? Or are these interim reports nothing more than an excuse to ignore proper evaluation of the collected data in true syntheses? What moral or ethical responsibility do we hold vis-à-vis the funding bodies of archaeological excavation or society at large?'

This was the challenge we presented to an international group of archaeologists at a round table entitled 'Why excavate?', which was held at the 16th Annual Meeting of the European Association of Archaeologists at The Hague, the Netherlands, on 2 September 2010. The session took a critical look at archaeological excavation and asked whether, in the modern Western world, it should still be the same defining practice of our discipline that it used to be (and, if so, what reforms might be needed to ensure the continuation of this central status). As some participants to the session noted in their oral presentations (as well as their written contributions included 
in this issue), the problem presented in the session's abstract was clearly written from a (north-west) European perspective. This choice was deliberate, as the planned venue for this dialogue was the EAA's annual meeting taking place in The Hague. The angle of observation was doubtless further determined by our own working bases in the Netherlands and Great Britain. Whilst being aware of great differences in the number, scale and practice of archaeological excavation across the European continent (not to speak of the rest of the world), we share a concern with the developments archaeology has been undergoing in our native countries since the implementation of the Valletta Treaty. The decentralized model that our countries have adopted in dealing with the protection of our cultural heritage and the excavation of archaeological sites under threat - with a decisive role for commercial parties competing to bid most cheaply in a free-market environment, with numerous short-term projects of little scientific value and with a minimal role for university departments in long-term research-led excavations - may have been profitable in terms of job creation, but poses a serious threat to the quality of archaeological fieldwork and the public support for archaeology in the long run (cf. Kristiansen 2009). Furthermore, with the ongoing debate on the selection of sites and quality standards of fieldwork and with the Dutch Monuments Act that brought the Valletta Treaty into implementation in the Netherlands now undergoing a first thorough review by order of the Dutch Parliament, the central question raised by the round table was thought to be both provocative and timely (even if a major change in the Dutch system is not to be expected).

The rapidly deteriorating economic situation in Europe is likely to have a major impact on both public- and private-sector funding for excavation in the immediate future. Even in the three months since the session took place, in September 2010, the economies of hitherto affluent European nations have been subject to further strain. Major cuts to public funding have been announced in the UK, Ireland, Belgium, Spain, France, the Netherlands and other countries. Archaeology, heritage and the kind of research that does not immediately translate into cash are not usually spending priorities when weighed against social care, health and education. An example of this was seen during a debate on the national budget in the Dutch parliament, in November 2010, when one of the MPs asked the state secretary for culture 'not to carry out an evaluation [i.e. of the Malta legislation] which will only be ready in a year and a half, but to take measures immediately so as to bring the archaeology industry, which swallows up millions of euros and is currently ravaging the Netherlands, to a halt'. In such a climate the serious examination of the necessity of excavation is even more urgent.

This issue of Archaeological dialogues includes the printed versions of five position papers that were commissioned by the journal from archaeologists working in a variety of professional capacities in several different traditions (for which, see the list of contributors at the end of this issue). After the formal oral presentation of these papers, the discussion was opened to the floor. Several discussants from the audience, whose comments seemed to bring in new points of view, were subsequently invited to commit these to print (Ndlovu, Edgeworth, Zubrow). Finally, one comment, by Rick Bonnie, came 
in spontaneously. Given the diverse responsibilities of today's community of archaeologists and their sometimes conflicting interests, it seemed clear in advance that we were not going to reach general consensus, but it is our hope that the tentative replies to the round table's central question presented here in print contribute to an ongoing discussion on the issue at stake, not just in lecture halls of conference venues or in the pages of this journal, but also at the edge of the excavation pit and, for better or worse, at all those administrative levels where decisions on archaeological fieldwork are taken.

Although the participants in the discussion all took different positions, there was a general consensus that excavation still has a central and indispensable role in archaeological research. While for many archaeologists excavation has remained a sort of 'second nature', according to Jean-Paul Demoule (p. 10), 'we do not have the choice: we have to excavate in order to increase the production of archaeological knowledge in still poorly documented parts of the world and in order to preserve the archaeological heritage of humanity for future generations'. This may sound laudable, but in large parts of western Europe the daily practice of excavation has become much more prosaic: archaeologists 'have become part of an unstoppable excavation machine' (Nilsson, this issue, p. 27), some of our junior colleagues have become the modern migrant slaves of developing and urban planning companies and many of us fear that contract excavations under the capitalist commercial system 'will lead to risk-free reproduction and deficient exchanges (and thus fragmentation) of knowledge' (Kolen, this issue, p. 31). The challenge facing our discipline now is to find ways of overcoming these problems. If we still want to excavate, we need to remain critical and reflexive, not just about our research questions, but about the very practice of fieldwork itself.

\section{Reference}

Kristiansen, K., 2009: Contract archaeology in Europe. An experiment in diversity, World archaeology 41(4), 641-48. 